\title{
Network meta-analysis and cost per responder of targeted Immunomodulators in the treatment of active psoriatic arthritis

Vibeke Strand ${ }^{1}$, M. Elaine Husni ${ }^{2}$, Keith A. Betts ${ }^{3 *}$, Yan Song ${ }^{4}$, Rakesh Singh ${ }^{5}$, Jenny Griffith ${ }^{5}$, Marci Beppu ${ }^{5}$, Jing Zhao ${ }^{4}$ and Arijit Ganguli ${ }^{5}$

\begin{abstract}
Background: Multiple targeted immunomodulators (TIMs) for psoriatic arthritis (PsA) treatment are available, but limited studies have directly compared these agents. This study indirectly compared the efficacy of TNF-a, interleukins, and phosphodiesterase-4 inhibitors for treatment of active PsA.

Methods: A systematic literature review was conducted to identify phase III randomized controlled trials (RCTs) for adalimumab, certolizumab pegol, etanercept, golimumab, infliximab, ustekinumab, secukinumab, and apremilast in active PsA. Joint (ACR20/50/70) and skin outcomes (PASI75/90) at Week 24 with each TIM were estimated via a Bayesian network meta-analysis, and the incremental cost per responder over the first 24 weeks of treatment was calculated. Similar analyses were conducted in a subgroup of biologic-naïve patients.

Results: Seventeen RCTs were identified; 13 included ACR and/or PASI responses at Week 24. Among the overall population, patients receiving adalimumab, golimumab, and infliximab showed higher ACR20/50/70 (adalimumab: 61.2/42.8/40.8\%, golimumab: 61.6/39.8/27.4\%, infliximab: 56.2/57.1/34.2\%) and PASI75/90 (72.7/55.5\%, 74.1/57.2\%, and $77.1 / 61.0 \%$, respectively) responses at Week 24 compared with other TIMs. In terms of cost-effectiveness, these treatments were also associated with the lowest incremental cost per responder for both skin and joint outcomes. Similar rankings of efficacy and incremental cost per responder were observed in the analysis among biologic-naive patients.

Conclusions: Adalimumab, golimumab, and infliximab were associated with higher efficacy and lower incremental costs per responder for both joint and skin responses in active PsA.
\end{abstract}

Keywords: Arthritis, psoriatic, Meta-analysis, Immunomodulators, Cost-benefit analysis

\section{Background}

Psoriatic arthritis (PsA) is a chronic inflammatory arthritis that occurs in up to $24 \%$ of psoriasis patients [1]. In the majority of PsA patients, skin symptoms precede the arthritis, and common manifestations of the disease may include synovitis, enthesitis, dactylitis, and anterior uveitis [2]. Similar to rheumatoid arthritis, PsA can be disabling and lead to erosive arthropathy in some patients [3]. A variety of therapeutic agents are available for the management of PsA, although the clinical heterogeneity of the disease poses a challenge to clinicians

\footnotetext{
*Correspondence: Keith.Betts@analysisgroup.com

${ }^{3}$ Analysis Group Inc., 333 South Hope Street, 27th Floor, Los Angeles, CA 90071, USA

Full list of author information is available at the end of the article
}

in determining the best treatment [4]. PsA patients with moderate to severe symptoms typically require disease modifying anti-rheumatic drugs (DMARDs), non-steroidal anti-inflammatory drugs (NSAIDs), phototherapy, or a combination of the three [5]. Recent studies have shown that traditional DMARDs, such as methotrexate, are ineffective for preventing progression of joint damage and may have serious adverse effects [6-8].

Immunomodulators (TIMs) such as tumor necrosis factor- $\alpha$ (TNF) inhibitors, interleukin inhibitors, and phosphodiesterase-4 inhibitors have dramatically changed the therapeutic paradigm of PsA [9]. Although demonstrated to be more effective than traditional DMARDs, the relative efficacy and cost-effectiveness of these newly investigated agents remains uncertain. Reliable evidence 
regarding the comparative efficacy of these novel PsA agents is crucial for informing clinical and economic decisions about their most appropriate use.

The objective of this study was to determine the comparative efficacy of these TIMs, as well as the incremental cost per responder over the first 24 weeks of treatment in patients with active PsA in the US. Since few head-to-head studies of these therapies have been performed, a network meta-analysis was conducted to synthesize all available evidence from randomized trials and enable indirect comparisons among competing interventions [10]. Detailed methodological reviews and implementation guidelines for network meta-analyses have been published [11, 12], and network meta-analyses have become a preferred source of evidence among researchers, medical decision makers, and health technology assessment agencies [12-14].

\section{Methods}

\section{Trial identification}

A systematic literature review was conducted to identify Phase III randomized controlled trials (RCTs) of TNF inhibitors (adalimumab, certolizumab pegol, etanercept, golimumab, and infliximab), interleukin inhibitors (secukinumab and ustekinumab), and a phosphodiesterase-4 inhibitor (apremilast) for active PsA. Trials were conducted in adult patients (age $\geq 18$ ) with active PsA, and included one of the TIMs listed above as active treatment versus placebo or versus another active comparator. RCTs were required to have reported clinical outcome measures for joint responses (by American College of Radiology [ACR] criteria) and/or skin responses (by Psoriasis Area and Severity Index [PASI]). ACR criteria is commonly used to assess the improvement in tender or swollen joint counts, acute phase reactant, patient and physician global assessments, pain scale, and disability/functionality questionnaire. PASI score evaluates the effectiveness of treatment through the assessment of psoriasis lesions in four body regions: head, upper extremities, trunk, and lower extremities. For inclusion, treatment arms were required to use the dose approved by the US Food and Drug Administration (FDA) for each TIM.

\section{Efficacy measures}

Joint responses were defined by the ACR20 (20\% improvement in ACR criteria), ACR50, and ACR70 response criteria [15]. PASI75 (75\% improvement in PASI) and PASI90 responses were used to define skin responses $[16,17]$. Efficacy measures at Week 24 were used in the current study, as they were the primary outcome measures for newly investigated agents, including ustekinumab and secukinumab.

\section{Costs}

Unit drug costs in the US as of May 8, 2017 were based on wholesale acquisition costs (WAC) obtained from ReadyPrice ${ }^{\circ}$. Dosing schedules for each TIM were based on FDA labeling. Costs for infliximab were based on treatment costs of an $80-\mathrm{kg}$ adult and administration costs (intravenous infusion) as of May 8, 2017 were obtained from the US Department of Health and Human Services (CPT code 96413 for the initial hour and 96415 for the subsequent $3 \mathrm{~h}$ ) $[18,19]$. Costs for each TIM over the first 24 weeks of treatment were calculated based on dosing schedules, acquisition costs, and infusion costs.

\section{Statistical methods}

A Bayesian network meta-analysis was conducted to assess the comparative efficacy (in terms of ACR20/50/ 70 and PASI75/90) of different TIMs in the treatment of active PsA. Using a fixed effect model, the number of patients achieving ACR20, ACR50, and ACR70 at Week 24 was assumed to follow a binomial distribution, with the corresponding probabilities linked to the treatment effects via a logit function. Non-informative priors were applied to the treatment effect parameter to ensure that treatment comparisons were driven by the observed data. Estimated ACR responses were summarized using posterior means and $95 \%$ credible intervals (CrI) for all treatments included in the network.

For the PASI outcomes, a fixed effect, ordinal model assumed that the number of patients achieving PASI50, PASI75, and PASI90 responses followed a multinomial distribution. A probit link was used to estimate the probability of each treatment achieving PASI responses based on all observed comparisons. This model allowed the three PASI outcomes to be analyzed jointly, and further assumed that each treatment had the same magnitude of additive effect versus placebo on subsequent levels of PASI responses on the inverse probit scale [20]. A non-informative prior was also specified for the response rates of the reference arm across all RCTs. Based on the model results, PASI75 and PASI90 responses for each therapy were estimated.

Numbers needed to treat (NNT) for each additional responder were calculated as the reciprocal of the difference in estimated response rate between active agent and placebo based on the network meta-analysis. Incremental cost per responder for each treatment relative to placebo was calculated as the product of the total costs over the first 24 weeks of treatment and the NNT. All analyses were conducted within a Bayesian framework and were estimated via Markov chain Monte Carlo using OpenBUGS 3.2.3. Analyses were repeated in the subset of patients without prior biologic treatment. 


\section{Results}

The systematic literature review identified 17 RCTs that met the inclusion criteria. One trial [21] was excluded because it was only 12 weeks in duration and three other trials [22-24] were excluded because placebo patients crossed over to active treatment prior to Week 24. The remaining 13 trials reported ACR and/or PASI responses at Week 24 after initiation of treatment (Additional file 1: Table S1). Proportion of patients with conventional DMARDs use and with methotrexate (MTX) use at baseline was summarized. Evidence networks of ACR and PASI outcomes among the overall population are shown in Fig. 1a and b, respectively.

Across the selected RCTs, 11 provided stratified results for biologic-naive patients or were conducted in a biologic-naive population (Additional file 2: Table S2). Although Mease 2004 [25] did not explicitly indicate biologic treatment experience of participants, they were assumed to be all biologic-naïve given the era in which this trial was conducted. PASI responses in biologic-naive PsA patients were not available for apremilast and certolizumab pegol. Evidence networks of ACR and PASI outcomes among the biologic-naïve population are shown in Additional file 3: Figure S1A and S1B, respectively.

\section{Network meta-analysis: ACR outcomes}

Among the overall population, three TNF inhibitors golimumab, adalimumab, and infliximab - demonstrated better ACR outcomes compared with other TIMs at Week 24. PsA patients treated with golimumab had the highest ACR20 responses (61.6\%), followed by adalimumab (61.2\%) and infliximab (56.2\%). In terms of ACR50, infliximab had the highest efficacy (57.1\%), followed by etanercept (46.6\%), adalimumab (42.8\%), and golimumab (39.8\%). In terms of ACR70, adalimumab (40.8\%), infliximab (34.2\%), and golimumab (27.4\%) had higher efficacy compared with other TIMs (Table 1).

Similar rankings of ACR20/50/70 responses and NNTs for the different TIMs were observed in the analysis among biologic-naive patients (Additional file 4: Table S3). Biologic-naive patients treated with golimumab, adalimumab, secukinumab, or infliximab had higher ACR20 responses compared with other TIMs. Infliximab, etanercept, adalimumab, and golimumab had numerically higher ACR50 responses compared with other TIMs. In terms of ACR70, adalimumab, infliximab, golimumab, and secukinumab had higher efficacy than other TIMs among the biologic-naïve PsA population.

\section{Network meta-analysis: PASI outcomes}

PsA patients treated with infliximab had the highest PASI75 responses at Week 24 (77.1\%), followed by golimumab (74.1\%), adalimumab (72.7\%), and secukinumab $300 \mathrm{mg}$ (60.4\%). In terms of PASI90, infliximab had the highest efficacy compared with other TIMs (61.0\%), followed by golimumab (57.2\%), adalimumab (55.5\%), and secukinumab $300 \mathrm{mg}$ (42.3\%). Detailed results of the NMA of PASI75 and PASI90 for all TIMs among the overall PsA population are shown in Table 2.

Similar rankings of TIMs in PASI75 and PASI90 responses and NNTs among biologic-naive patients were observed. Among biologic-naive patients, infliximab, golimumab, and adalimumab showed higher PASI75 and PASI90 responses than other TIMs while etanercept had lower efficacy in PASI outcomes. a Evidence network of ACR outcomes

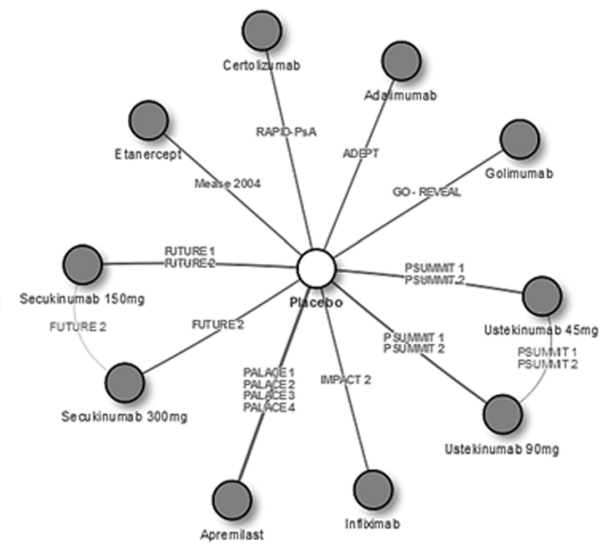

b Evidence network of PASI outcomes

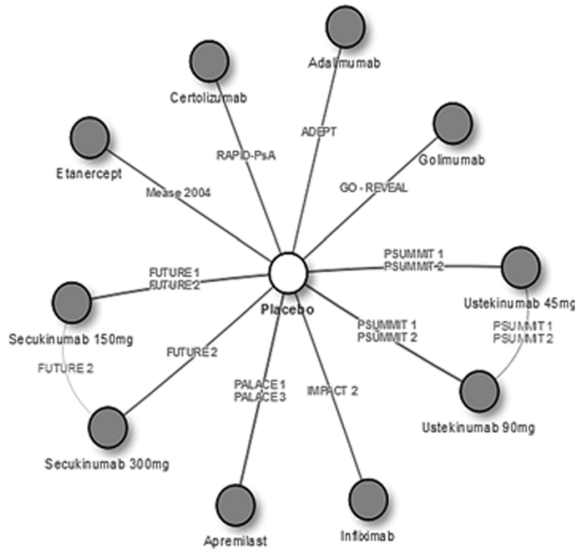

Fig. 1 Evidence network for ACR and PASI outcomes among the overall population. a Thirteen trials reported ACR responses at Week 24 were selected: ADEPT [34], PALACE 1 [39], PALACE 2 [40], PALACE 3 [41-43], PALACE 4 [44, 45], RAPID-PsA [46], Mease 2004 [25], GO-REVEAL [47], IMPACT 2 [48], FUTURE 1 [49], FUTURE 2 [50], PSUMMIT 1 [51], and PSUMMIT 2 [52]. (b) Eleven trials reported PASI responses at Week 24 were selected: ADEPT [34], PALACE 1 [39], PALACE 3 [41-43], RAPID-PSA [46], Mease 2004 [25], GO-REVEAL [47], IMPACT 2 [48], FUTURE 1 [49], FUTURE 2 [50], PSUMMIT 1 [51], and PSUMMIT 2 [52]. 
Table 1 ACR response rates and NNT at Week 24 among the overall population

\begin{tabular}{|c|c|c|c|c|c|c|}
\hline \multirow[t]{2}{*}{ Treatment } & \multicolumn{2}{|l|}{ ACR20 } & \multicolumn{2}{|l|}{ ACR50 } & \multicolumn{2}{|l|}{ ACR70 } \\
\hline & $\begin{array}{l}\text { Response rate } \\
(95 \% \mathrm{Crl})\end{array}$ & $\begin{array}{l}\text { NNT } \\
(95 \% \text { Crl) }\end{array}$ & $\begin{array}{l}\text { Response rate } \\
(95 \% \text { Crl) }\end{array}$ & $\begin{array}{l}\text { NNT } \\
(95 \% \text { Crl) }\end{array}$ & $\begin{array}{l}\text { Response rate } \\
(95 \% \mathrm{Crl})\end{array}$ & $\begin{array}{l}\text { NNT } \\
(95 \% \text { Crl) }\end{array}$ \\
\hline Placebo & $17.0 \%(15.4 \%, 18.7 \%)$ & - & $7.0 \%(5.9 \%, 8.2 \%)$ & - & $2.5 \%(1.9 \%, 3.3 \%)$ & - \\
\hline Adalimumab & $61.2 \%(47.8 \%, 73.6 \%)$ & $2.3(1.8,3.2)$ & $42.8 \%(27.0 \%, 62.5 \%)$ & $2.8(1.8,4.9)$ & $40.8 \%(15.9 \%, 82.2 \%)$ & $2.6(1.3,7.4)$ \\
\hline Apremilast & $33.4 \%(27.1 \%, 40.4 \%)$ & $6.1(4.4,9.5)$ & $15.5 \%$ (10.9\%, 21.8\%) & $11.8(7.0,23.5)$ & $5.0 \%(2.7 \%, 9.1 \%)$ & $40.3(15.8,222.7)$ \\
\hline Certolizumab pegol & $50.2 \%(38.6 \%, 62.3 \%)$ & $3.0(2.2,4.6)$ & $27.9 \%(18.0 \%, 41.8 \%)$ & $4.8(2.9,8.9)$ & $16.7 \%$ (7.9\%, 35.9\%) & $7.0(3.0,17.8)$ \\
\hline Etanercept & $50.1 \%(35.2 \%, 65.5 \%)$ & $3.0(2.1,5.4)$ & $46.6 \%(26.6 \%, 71.2 \%)$ & $2.5(1.6,5.1)$ & $9.1 \%(2.7 \%, 32.6 \%)$ & $15.2(3.3,318.5)$ \\
\hline Golimumab & $61.6 \%(45.9 \%, 76.3 \%)$ & $2.2(1.7,3.4)$ & $39.8 \%(22.0 \%, 64.7 \%)$ & $3.1(1.7,6.6)$ & $27.4 \%(9.2 \%, 71.8 \%)$ & $4.0(1.4,14.6)$ \\
\hline Infliximab & $56.2 \%(39.9 \%, 72.2 \%)$ & $2.6(1.8,4.3)$ & $57.1 \%(32.7 \%, 82.5 \%)$ & $2.0(1.3,3.9)$ & $34.2 \%(12.1 \%, 77.9 \%)$ & $3.2(1.3,10.3)$ \\
\hline Secukinumab 150 mg & $51.1 \%(414 \%, 61.0 \%)$ & $2.9(2.3,4.0)$ & $33.8 \%(23.5 \%, 46.8 \%)$ & $3.7(2.5,6.0)$ & $27.3 \%(13.4 \%, 53.1 \%)$ & $4.0(2.0,9.0)$ \\
\hline Secukinumab 300 mg & $55.2 \%(41.0 \%, 68.8 \%)$ & $2.6(1.9,4.1)$ & $34.0 \%(20.6 \%, 51.0 \%)$ & $3.7(2.3,7.2)$ & $27.0 \%(11.3 \%, 55.7 \%)$ & $4.1(1.9,11.1)$ \\
\hline Ustekinumab 45 mg & $35.4 \%(27.5 \%, 44.4 \%)$ & $5.4(3.7,9.2)$ & $19.9 \%(13.0 \%, 29.9 \%)$ & $7.7(4.4,15.8)$ & $10.2 \%(4.8 \%, 21.9 \%)$ & $13.0(5.2,39.7)$ \\
\hline Ustekinumab 90 mg & $39.9 \%(31.5 \%, 49.1 \%)$ & $4.4(3.2,6.7)$ & $23.5 \%(15.6 \%, 34.3 \%)$ & $6.1(3.7,11.1)$ & $12.1 \%(5.9 \%, 25.2 \%)$ & $10.4(4.4,27.8)$ \\
\hline
\end{tabular}

Crl credible interval, NNT number needed to treat

Detailed results among the biologic-naïve population are shown in Additional file 5: Table S4.

\section{Network meta-analysis: Incremental cost per responder over 24 weeks}

From a cost-effectiveness perspective, infliximab, adalimumab, and golimumab have demonstrated lower incremental cost per responder in both joint and skin outcomes compared to other TIMs. Evaluation of the cost-effectiveness over 24 weeks revealed that infliximab ( $\$ 48,859$ for ACR50/ $\$ 35,277$ for PASI75), adalimumab (\$74,438 for ACR50/\$41,013 for PASI75), and golimumab (\$75,966 for ACR50/\$37,542 for PASI75) were associated with the lowest incremental costs per additional ACR50 responder and per additional PASI75 responder (Fig. 2a). Similar conclusions can be reached using incremental cost per responder for ACR70 and PASI90. Adalimumab ( $\$ 69,641$ for ACR70/ $\$ 50,717$ for PASI90), infliximab (\$77,347 for ACR70/ $\$ 42,171$ for PASI90), and golimumab (\$100,158 for ACR70/\$45,926 for PASI90) were associated with the lowest incremental costs per responder over 24 weeks (Fig. 2b).

A similar ranking of these TIMs in terms of costeffectiveness was observed in the biologic-naïve population. Infliximab, adalimumab, and golimumab were consistently associated with lower incremental cost per responder over 24 weeks in both joint and skin outcomes compared to other TIMs (Additional file 6: Figure S2A and S2B). Detailed results of incremental costs per responder for all ACR and PASI outcomes among overall and biologic-naïve populations are shown in Additional files 7 and 8: Tables S5 and S6, respectively.

Table 2 PASI response rates and NNT at Week 24 among the overall population

\begin{tabular}{|c|c|c|c|c|}
\hline \multirow[t]{2}{*}{ Treatment } & \multicolumn{2}{|l|}{ PASI75 } & \multicolumn{2}{|l|}{ PASI90 } \\
\hline & Response (95\% Crl) & NNT (95\% Crl) & Response $(95 \% \mathrm{Crl})$ & NNT $(95 \%$ Crl) \\
\hline Placebo & $7.6 \%(5.2 \%, 10.8 \%)$ & - & $2.9 \%(1.8 \%, 4.5 \%)$ & - \\
\hline Adalimumab & $72.7 \%(54.0 \%, 86.7 \%)$ & $1.5(1.3,2.1)$ & $55.5 \%(36.0 \%, 74.3 \%)$ & $1.9(1.4,3.0)$ \\
\hline Apremilast & $23.9 \%(14.1 \%, 36.5 \%)$ & $6.2(3.6,13.3)$ & $12.0 \%(6.1 \%, 21.0 \%)$ & $11.0(5.7,26.5)$ \\
\hline Certolizumab pegol & $45.6 \%(31.6 \%, 60.4 \%)$ & $2.6(1.9,4.0)$ & $28.4 \%(17.4 \%, 42.1 \%)$ & $3.9(2.6,6.7)$ \\
\hline Etanercept & $26.0 \%(12.9 \%, 44.1 \%)$ & $5.5(2.8,16.7)$ & $13.4 \%(5.5 \%, 27.1 \%)$ & $9.6(4.2,34.1)$ \\
\hline Golimumab & $74.1 \%(56.1 \%, 87.7 \%)$ & $1.5(1.3,2.0)$ & $57.2 \%$ (37.9\%, 75.8\%) & $1.8(1.4,2.8)$ \\
\hline Infliximab & $77.1 \%(60.5 \%, 89.5 \%)$ & $1.4(1.2,1.9)$ & $61.0 \%(42.4 \%, 78.8 \%)$ & $1.7(1.3,2.5)$ \\
\hline Secukinumab 150 mg & $50.3 \%(36.1 \%, 65.3 \%)$ & $2.3(1.8,3.4)$ & $32.4 \%(20.6 \%, 47.2 \%)$ & $3.4(2.3,5.5)$ \\
\hline Secukinumab 300 mg & 60.4\% (39.7\%, 79.2\%) & $1.9(1.4,3.0)$ & $42.3 \%(23.6 \%, 63.7 \%)$ & $2.5(1.7,4.8)$ \\
\hline Ustekinumab 45 mg & $51.2 \%(37.5 \%, 64.8 \%)$ & $2.3(1.8,3.2)$ & $33.2 \%(21.8 \%, 46.6 \%)$ & $3.3(2.3,5.1)$ \\
\hline Ustekinumab 90 mg & $58.2 \%(44.7 \%, 70.8 \%)$ & $2.0(1.6,2.6)$ & $39.9 \%$ (27.5\%, 53.4\%) & $2.7(2.0,4.0)$ \\
\hline
\end{tabular}



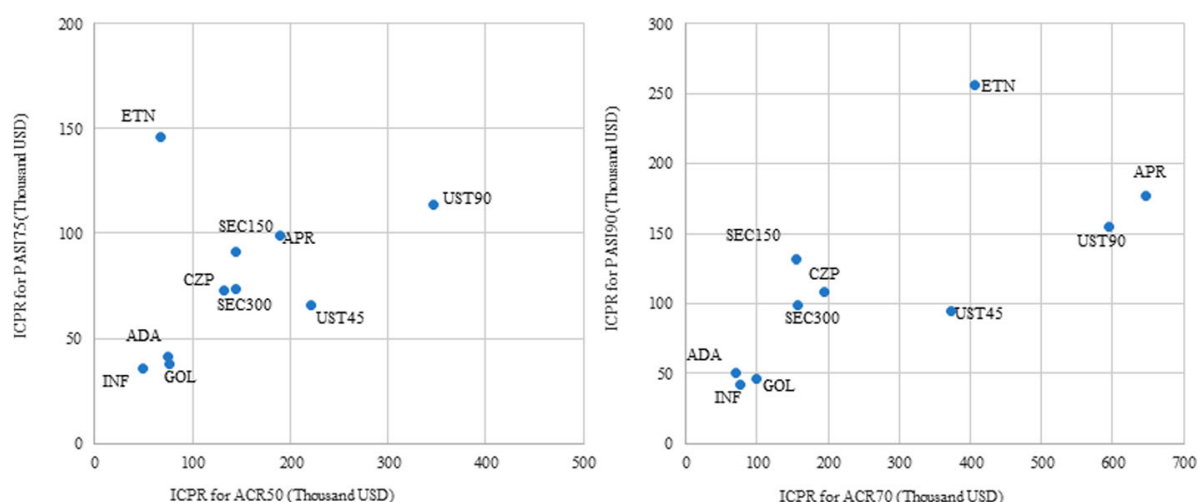

Fig. 2 Incremental cost per responder over 24 weeks among the overall population. a Incremental cost per additional ACR50 responder vs. incremental cost per additional PASI75 responder. $\mathbf{b}$ Incremental cost per additional ACR70 responder vs. incremental cost per additional PASI90 responder. ADA, adalimumab; APR, apremilast; CZP, certolizumab pegol; ETN, etanercept; GOL, golimumab; IFX, infliximab; SEC 150, secukinumab 150 mg; SEC 300 , secukinumab 300 mg; UST 45, ustekinumab 45 mg; UST 90, ustekinumab 90 mg

\section{Discussion}

The treatment goal for PsA is to improve signs and symptoms of disease, including both peripheral arthritis (which is associated with radiographic progression and deterioration of physical function) and skin disease (which is associated with mental health and impaired quality of life) [26-28]. In this network meta-analysis, adalimumab, golimumab, and infliximab showed better efficacy and cost-effectiveness relative to other TIMs in both joint and skin outcomes. Specifically, these treatments had the lowest NNTs and incremental costs per additional responder over 24 weeks across all evaluated TIMs among the overall population as well as the biologic-naïve population. The rankings of other TIMs in terms of response rate, $\mathrm{NNT}$, and incremental costs per additional responder were similar in the overall and biologic-naïve populations.

Several previous network meta-analyses / economic evaluations have investigated the efficacy and costeffectiveness of TIMs for PsA. One conducted from the UK NHS perspective included adalimumab, etanercept, golimumab, and infliximab and concluded that etanercept was cost-effective - with similar joint responses by PsA response criteria (PsARC) despite lower PASI responses compared to adalimumab, golimumab, and infliximab $[29,30]$. Another study, based on the same set of RCTs, concluded that golimumab and etanercept were associated with higher PsARC responses compared with adalimumab and infliximab [31]. Limitations of both analyses include inconsistent time points for outcome measurement. Thorlund et al. [31] used the last observed time point as the primary endpoint despite including some studies with only Week 12 endpoints [21,23] and others with Week 24 endpoints. In the current systematic literature review, studies reporting only Week 12 outcomes were excluded from analyses to facilitate a fair comparison across TIMs. In addition, a third study (McInnes 2016) concluded comparable response rates between secukinumab and TNF inhibitors across all ACR outcomes in the mixed population of biologic-naïve and biologic-experienced PsA patients [32]. A recent meta-analysis conducted by Dongze et al. evaluated efficacy and safety of anticytokine biologic agents including secukinumab, ustekinumab, clazakizumab, and ixekizumab for active PsA at Week 24 and concluded that secukinumab and ustekinumab were the most efficacious short-term treatments among assessed agents [33]. Clazakizumab and ixekizumab were not included in this study since neither was approved as treatment for PsA at the time of the analysis.

Previous studies focused on PsARC as the measure of articular response, defined by $\geq 30 \%$ improvement in tender or swollen joint counts and one-point improvement in patient or physician global assessment of disease activity on a five-point Likert scale. In contrast, ACR response criteria also include visual analogue scale (VAS) scores of patient reported pain, Health Assessment Questionnaire (HAQ), and acute phase reactants. ACR responses are considered more stringent and comprehensive, and have become the primary outcome measure in a majority of RCTs in PsA [34]. Consequently, the current analysis chose ACR over PsARC responses as the measure of joint responses in PsA.

Biologic-naïve PsA patients generally report higher absolute joint and skin responses; however, comparative efficacy and cost-effectiveness in this population has not been systematically reviewed. Two recent meta-analysis studies comparing the efficacy of TIMs in biologic-naïve PsA patients concluded that ACR responses were higher among TNF inhibitors (etanercept, infliximab, adalimumab, and golimumab) and secukinumab, compared 
with other TIMs such as apremilast and ustekinumab [32, 35]. Another meta-analysis study conducted in a biologic-naïve PsA population in a Taiwanese setting found that etanercept had lower annual costs per PsARC and ACR20 responders than adalimumab and golimumab [36]. The above-mentioned studies only considered joint outcomes from Week 12 to Week 16, whereas the current study assessed efficacy in terms of both joint and skin outcomes at Week 24, as well as the cost-effectiveness of these TIMs. The longer time frame, inclusion of additional clinically relevant endpoints, and the cost analysis attest to the greater strength of the evidence presented in our study. The current analyses are in fact the first to include the more recently approved treatments (including ustekinumab, certolizumab pegol, secukinumab, and apremilast) and comprehensively evaluate their comparative efficacy and cost-effectiveness.

This network meta-analysis is subject to limitations commonly present in indirect comparison studies, despite synthesizing data from RCTs. Network metaanalyses may be biased due to the heterogeneity of patient populations across different trials. Although they adjust for placebo treatment responses which may account for trial-specific factors likely to influence outcomes in the active treatment arms, such adjustment only reduces the between-study heterogeneity. Moreover, due to the relatively small numbers of eligible RCTs for each pairwise comparison in this network meta-analysis, it was not possible to adjust for baseline risks within each trial. One specific limitation was that biologic-naïve data were not available for apremilast or certolizumab, and biologic-naïve results for secukinumab were based on a small sample size, which limited potential comparative interpretation. In addition, due to the lack of published data on patients who achieve both responses in terms of both joint and skin outcomes, the efficacy and cost-effectiveness of dual responses could not be assessed. However, treatment decisions should be based upon comprehensive considerations of both aspects. Despite the above limitations, this network meta-analysis represents the best evidence available to assess the comparative efficacy of currently available TIMs among PsA patients to inform health technology assessments and other decision-making $[20,37,38]$.

\section{Conclusions}

This study demonstrated the comparative efficacy and cost-effectiveness of TNF inhibitors, interleukin inhibitors, and phosphodiesterase- 4 inhibitors for patients with active PsA in the US. Adalimumab, infliximab, and golimumab demonstrated better efficacy and lower incremental costs per responder by both joint and skin responses across all PsA patients as well as biologicnaive PsA patients. In the absence of comparative evidence from head-to-head trials, these results can inform more cost-effective use of these TIMs.

\section{Additional files}

\begin{abstract}
Additional file 1: Table S1. Summary of results at Week 24 from included trials for the overall population. (DOCX $40 \mathrm{~kb}$ )

Additional file 2: Table S2. Summary of results at Week 24 from included trials among biologic-naïve population. (DOCX $36 \mathrm{~kb}$ )

Additional file 3: Figure S1A. Evidence network for ACR and PASI outcomes among biologic-naïve population (A) Eleven trials reported ACR responses at Week 24 were selected: ADEPT [34], PALACE 1 [39], PALACE 4 [44, 45], RAPID-PsA [46], Mease 2004 [25], GO-REVEAL [47], IMPACT 2 [48], FUTURE 1 [49], FUTURE 2 [50], PSUMMIT 1 [51], and PSUMMIT 2 [52]. (B) Seven trials reported PASI responses at Week 24 were selected: ADEPT [34], Mease 2004 [25], GO-REVEAL [47], IMPACT 2 [48], FUTURE 2 [50], PSUMMIT 1 [51], and PSUMMIT 2 [52]. (TIFF 352 kb)

Additional file 4: Table S3. ACR response rates and NNT at Week 24 among biologic-naïve population. (DOCX $13 \mathrm{~kb}$ )

Additional file 5: Table S4. PASI response rates and NNT at Week 24 among biologic-naïve population ${ }^{1}$. (DOCX $12 \mathrm{~kb}$ )

Additional file 6: Figure S2. Incremental cost per responder over 24 weeks among the biologic-naïve population. (A) Incremental cost per additional ACR50 responder vs. Incremental cost per additional PASI75 responder. (B) Incremental cost per additional ACR70 responder vs. Incremental cost per additional PASI90 responder. PASI responses were not reported for certolizumab pegol or apremilast in the biologic-naïve population. ADA, adalimumab; ETN, etanercept; GOL, golimumab; IFX, infliximab; SEC 150, secukinumab 150 mg; SEC 300, secukinumab 300 mg; UST 45, ustekinumab 45 mg; UST 90, ustekinumab 90 mg. (TIFF 105 kb)
\end{abstract}

Additional file 7: Table S5. Incremental cost per responder over 24 weeks among the overall PsA population. (DOCX $13 \mathrm{~kb}$ )

Additional file 8: Table S6. Incremental cost per responder over 24 weeks among biologic-naïve population. (DOCX $13 \mathrm{~kb}$ )

\section{Acknowledgements}

The authors would like to thank Fan Wu from Analysis Group and Bill Reichmann, a former employee of Analysis Group, for significant contribution towards medical writing and analytical support. This support was funded by AbbVie.

\section{Funding}

The design, study conduct, and financial support for the study were provided by AbbVie. AbbVie participated in the interpretation of data, review, and approval of the publication.

\section{Availability of data and materials}

All data generated or analysed during this study are included in this published article and its supplementary information files.

\section{Authors' contributions}

VS and $\mathrm{MH}$ contributed to the data interpretation and revision of the manuscript. KB, YS, and JZ contributed to the conception or design of the work, data collection, data analysis, data interpretation, and writing and revision of the manuscript. $\mathrm{RS}, \mathrm{JG}, \mathrm{MB}$, and $\mathrm{AG}$ contributed to the conception or design of the work, data interpretation, and revision of the manuscript. All named authors meet the International Committee of Medical Journal Editors (ICMJE) criteria for authorship for this manuscript, take responsibility for the integrity of the work as a whole, and have given final approval to the version to be published.

Ethics approval and consent to participate Not applicable 


\section{Consent for publication}

Not applicable

\section{Competing interests}

VS has served as consultant to AbbVie, Amgen, AstraZeneca, BMS, Boehringer Ingelheim, Celltrion, Genentech / Roche, GlaxoSmithKline, Janssen, Lilly, Merck, Novartis, Pfizer, Sandoz, UCB; MH, KB, YS, and JZ have served as consultants to AbbVie. RS, JG, MB, and AG are employees of AbbVie and may own company stock.

\section{Publisher's Note}

Springer Nature remains neutral with regard to jurisdictional claims in published maps and institutional affiliations.

\section{Author details}

${ }^{1}$ Stanford University, Palo Alto, CA, USA. ${ }^{2}$ Cleveland Clinic, Cleveland, OH, USA. ${ }^{3}$ Analysis Group Inc., 333 South Hope Street, 27th Floor, Los Angeles, CA 90071, USA. ${ }^{4}$ Analysis Group Inc., Boston, MA, USA. ${ }^{5}$ AbbVie Inc., Mettawa, IL, USA.

\section{Received: 16 November 2017 Accepted: 23 January 2018}

\section{Published online: 12 February 2018}

\section{References}

1. Prey S, Paul C, Bronsard V, Puzenat E, Gourraud PA, Aractingi S, et al. Assessment of risk of psoriatic arthritis in patients with plaque psoriasis: a systematic review of the literature. J Eur Acad Dermatol Venereol. 2010;24(Suppl 2):31-5.

2. Huynh D, Kavanaugh A. Psoriatic arthritis: current therapy and future approaches. Rheumatology. 2015;54(1):20-8.

3. Lee S, Mendelsohn A, Sarnes E. The burden of psoriatic arthritis: a literature review from a global health systems perspective. P \& T: a peer-reviewed journal for formulary management. 2010;35(12):680-9.

4. Cantini F, Niccoli L, Nannini C, Cassara E, Kaloudi O, Giulio Favalli E, et al. Tailored first-line biologic therapy in patients with rheumatoid arthritis, spondyloarthritis, and psoriatic arthritis. Semin Arthritis Rheum. 2016:45(5):519-32

5. Gottlieb A, Korman NJ, Gordon KB, Feldman SR, Lebwohl M, Koo JY, et al. Guidelines of care for the management of psoriasis and psoriatic arthritis: section 2. Psoriatic arthritis: overview and guidelines of care for treatment with an emphasis on the biologics. J Am Acad Dermatol. 2008:58(5):851-64.

6. Soriano ER, McHugh NJ. Therapies for peripheral joint disease in psoriatic arthritis. A systematic review. J Rheumatol. 2006;33(7):1422-30.

7. Gottlieb AB. Psoriasis - enhanced epidermal differentiation and reduced cellmediated inflammation are unexpected outcomes. Dis Manag Clin Outcomes. 1998;1(6):195-202.

8. Gottlieb AB. Novel immunotherapies for psoriasis: clinical research delivers new hope for patients and scientific advances. The journal of investigative dermatology Symposium proceedings / the Society for Investigative Dermatology, Inc [and] European Society for Dermatological Research. 2004;9(1):79-83.

9. Gottlieb AB. Psoriasis: emerging therapeutic strategies. Nat Rev Drug Discov. 2005:4(1):19-34

10. LU G, Ades AE. Combination of direct and indirect evidence in mixed treatment comparisons. Stat Med. 2004;23(20):3105-24.

11. Dias S, Welton NJ, Sutton AJ, Ades A. NICE DSU Technical Support Document 1: Introduction to evidence synthesis for decision making. University of Sheffield, Decision Support Unit 2011:1-24

12. Jansen JP, Fleurence $R$, Devine $B$, Itzler $R$, Barrett $A$, Hawkins $N$, et al. Interpreting indirect treatment comparisons and network meta-analysis for health-care decision making: report of the ISPOR task force on indirect treatment comparisons good research practices: part 1. Value Health. 2011:14(4):417-28.

13. Sutton A, Ades A, Cooper N, Abrams K. Use of indirect and mixed treatment comparisons for technology assessment. PharmacoEconomics. 2008;26(9):753-67.

14. Ritchlin CT, Kavanaugh A, Gladman DD, Mease PJ, Helliwell P, Boehncke WH, et al. Treatment recommendations for psoriatic arthritis. Ann Rheum Dis. 2009;68(9):1387-94.

15. Felson DT, Anderson JJ, Boers M, Bombardier C, Chernoff M, Fried B, et al. The American College of Rheumatology preliminary core set of disease activity measures for rheumatoid arthritis clinical trials. The committee on outcome measures in rheumatoid arthritis clinical trials. Arthritis Rheum 1993:36(6):729-40

16. Langley RG, Ellis CN. Evaluating psoriasis with psoriasis area and severity index, psoriasis global assessment, and lattice system Physician's global assessment. J Am Acad Dermatol. 2004;51(4):563-9.

17. Louden BA, Pearce DJ, Lang W, Feldman SR. A simplified psoriasis area severity index (SPASI) for rating psoriasis severity in clinic patients. Dermatol Online J. 2004;10(2):7.

18. Johnson \& Johnson Health Care Systems Inc. Reimbursement Resources (Remicade) 2017 [cited 2017 May 8]. Available from: https://www. janssencarepath.com/hcp/remicade/reimbursement.

19. Feldman SR, Garton R, Averett W, Balkrishnan R, Vallee J. Strategy to manage the treatment of severe psoriasis: considerations of efficacy, safety and cost. Expert Opin Pharmacother. 2003;4(9):1525-33.

20. Signorovitch JE, Betts KA, Yan YS, LeReun C, Sundaram M, Wu EQ, et al. Comparative efficacy of biological treatments for moderate-to-severe psoriasis: a network meta-analysis adjusting for cross-trial differences in reference arm response. Br J Dermatol. 2015;172(2):504-12.

21. Mease PJ, Goffe BS, Metz J, VanderStoep A, Finck B, Burge DJ. Etanercept in the treatment of psoriatic arthritis and psoriasis: a randomised trial. Lancet. 2000;356(9227):385-90.

22. Antoni CE, Kavanaugh A, Kirkham B, Tutuncu Z, Burmester GR, Schneider $U$, et al. Sustained benefits of infliximab therapy for dermatologic and articular manifestations of psoriatic arthritis: results from the infliximab multinational psoriatic arthritis controlled trial (IMPACT). Arthritis Rheum. 2005:52(4):1227-36.

23. Genovese MC, Mease PJ, Thomson GT, Kivitz AJ, Perdok RJ, Weinberg MA, et al. Safety and efficacy of adalimumab in treatment of patients with psoriatic arthritis who had failed disease modifying antirheumatic drug therapy. J Rheumatol. 2007;34(5):1040-50.

24. Gottlieb A, Menter A, Mendelsohn A, Shen YK, Li S, Guzzo C, et al. Ustekinumab, a human interleukin 12/23 monoclonal antibody, for psoriatic arthritis: randomised, double-blind, placebo-controlled, crossover trial. Lancet. 2009:373(9664):633-40

25. Mease PJ, Kivitz AJ, Burch FX, Siegel EL, Cohen SB, Ory P, et al. Etanercept treatment of psoriatic arthritis: safety, efficacy, and effect on disease progression. Arthritis Rheum. 2004;50(7):2264-72.

26. Coates LC, Kavanaugh A, Ritchlin CT, Committee GTG. Systematic review of treatments for psoriatic arthritis: 2014 update for the GRAPPA. J Rheumatol. 2014:41(11):2273-6.

27. Kavanaugh AF, Ritchlin CT, Committee GTG. Systematic review of treatments for psoriatic arthritis: an evidence based approach and basis for treatment guidelines. J Rheumatol. 2006;33(7):1417-21.

28. Sampogna F, Tabolli S, Soderfeldt B, Axtelius B, Aparo U, Abeni D, et al. Measuring quality of life of patients with different clinical types of psoriasis using the SF-36. Br J Dermatol. 2006;154(5):844-9.

29. Cawson MR, Mitchell SA, Knight C, Wildey H, Spurden D, Bird A, et al. Systematic review, network meta-analysis and economic evaluation of biological therapy for the management of active psoriatic arthritis. BMC Musculoskelet Disord. 2014;15:26.

30. Lubrano E, Spadaro A. Pharmacoeconomic burden in the treatment of psoriatic arthritis: from systematic reviews to real clinical practice studies. BMC Musculoskelet Disord. 2014;15:25.

31. Thorlund K, Druyts E, Avina-Zubieta JA, Mills EJ. Anti-tumor necrosis factor (TNF) drugs for the treatment of psoriatic arthritis: an indirect comparison meta-analysis. Biologics. 2012;6:417-27.

32. Mclnnes IB, Nash P, Ritchlin C, Thom H, Kanters S, Palaka E, et al. THU0437 Secukinumab for the treatment of psoriatic arthritis: comparative effectiveness results versus licensed biologics and Apremilast from a network meta-analysis. Ann Rheum Dis. 2016;75(Suppl 2):348-9.

33. Dongze $W$, Jiang Y, Tam L. FRI0523 short-term efficacy and safety of new biological agents targeting the IL-6, IL-12/23 and IL-17 pathways for active psoriatic arthritis: a network meta-analysis of randomised controlled trials: BMJ Publishing Group Ltd; 2017.

34. Mease PJ, Gladman DD, Ritchlin CT, Ruderman EM, Steinfeld SD, Choy EH, et al. Adalimumab for the treatment of patients with moderately to severely active psoriatic arthritis: results of a double-blind, randomized, placebocontrolled trial. Arthritis Rheum. 2005:52(10):3279-89.

35. Ungprasert $P$, Thongprayoon C, Davis JM 3rd. Indirect comparisons of the efficacy of biological agents in patients with psoriatic arthritis with an inadequate response to traditional disease-modifying anti-rheumatic drugs 
or to non-steroidal anti-inflammatory drugs: a meta-analysis. Semin Arthritis Rheum. 2016;45(4):428-38.

36. Yang TS, Chi CC, Wang SH, Lin JC, Lin KM. Cost-efficacy of biologic therapies for psoriatic arthritis from the perspective of the Taiwanese healthcare system. International journal of rheumatic diseases. 2016;19(10):1002-9.

37. Singh JA, Christensen R, Wells GA, Suarez-Almazor ME, Buchbinder R, LopezOlivo MA, et al. A network meta-analysis of randomized controlled trials of biologics for rheumatoid arthritis: a Cochrane overview. Can Med Assoc J. 2009;181(11):787-96.

38. Wandel S, Juni P, Tendal B, Nuesch E, Villiger PM, Welton NJ, et al. Effects of glucosamine, chondroitin, or placebo in patients with osteoarthritis of hip or knee: network meta-analysis. BMJ. 2010;341:C4675.

39. Kavanaugh A, Mease PJ, Gomez-Reino JJ, Adebajo AO, Wollenhaupt J, Gladman DD, et al. Treatment of psoriatic arthritis in a phase 3 randomised, placebo-controlled trial with apremilast, an oral phosphodiesterase 4 inhibitor. Ann Rheum Dis. 2014;73(6):1020-6.

40. Cutolo M, Myerson GE, Fleischmann RM, Liote F, Diaz-Gonzalez F, Van den Bosch F, et al. Long-term (52-week) results of a phase 3, randomized, controlled trial of Apremilast, an oral Phosphodiesterase 4 inhibitor, in patients with psoriatic arthritis (PALACE 2). Arthritis Rheum. 2013;65(Suppl 10):815

41. Edwards CJ, Blanco FJ, Crowley J, Hu C, Stevens RM, Birbara CA. Longterm 52-week results of Palace 3, a phase 3, randomized, controlled trial of Apremilast, an oral Phosphodiesterase 4 inhibitor, in patients with psoriatic arthritis and current skin involvement. Arthritis Rheum. 2014;53(Suppl 1):138-9.

42. Birbara C, Blanco FJ, Crowley JJ, Hu C, Stevens R, Edwards CJ. Efficacy of apremilast, an oral phosphodiesterase 4 inhibitor, on physical function and pain in patients with psoriatic arthritis, including current skin involvement: results of a phase 3, randomized, controlled trial. Ann Rheum Dis. 2013; 72(Suppl 3):678

43. National Institutes of Health. PALACE 3: Efficacy and Safety Study of Apremilast to Treat Active Psoriatic Arthritis 2015 [cited 2015 August 3]. Available from: https://clinicaltrials.gov/ct2/show/results/NCT01212770.

44. Wells AF, Edwards CJ, Adebajo AO, Kivitz AJ, Bird P, Shah K, et al., editors. Apremilast in the treatment of DMARD-naïve psoriatic arthritis patients: results of a phase 3 randomized, controlled trial (PALACE 4). 2013 ACR/ARHP annual meeting late-breaking abstracts; 2013 October 25-30, 2013; San Diego, CA.

45. ClinicalTrials.gov. Efficacy and Safety Study of Apremilast to Treat Active Psoriatic Arthritis (PSA) (PALACE4) 2014 [cited 2015 July 6]. Available from: https://clinicaltrials.gov/ct2/show/results/NCT01307423.

46. Mease PJ, Fleischmann R, Deodhar AA, Wollenhaupt J, Khraishi M, Kielar D, et al. Effect of certolizumab pegol on signs and symptoms in patients with psoriatic arthritis: 24-week results of a phase 3 double-blind randomised placebo-controlled study (RAPID-PsA). Ann Rheum Dis. 2014;73(1):48-55.

47. Kavanaugh A, McInnes I, Mease P, Krueger GG, Gladman D, Gomez-Reino J, et al. Golimumab, a new human tumor necrosis factor alpha antibody, administered every four weeks as a subcutaneous injection in psoriatic arthritis: twenty-four-week efficacy and safety results of a randomized, placebo-controlled study. Arthritis Rheum. 2009;60(4):976-86.

48. Antoni C, Krueger GG, de Vlam K, Birbara C, Beutler A, Guzzo C, et al. Infliximab improves signs and symptoms of psoriatic arthritis: results of the IMPACT 2 trial. Ann Rheum Dis. 2005;64(8):1150-7.

49. Mease PJ, McInnes IB, Kirkham B, Kavanaugh A, Rahman P, van der Heijde D, et al. Secukinumab inhibition of interleukin-17A in patients with psoriatic arthritis. N Engl J Med. 2015;373(14):1329-39.

50. Mclnnes IB, Mease PJ, Kirkham B, Kavanaugh A, Ritchlin CT, Rahman P, et al. Secukinumab, a human anti-interleukin-17A monoclonal antibody, in patients with psoriatic arthritis (FUTURE 2): a randomised, double-blind, placebo-controlled, phase 3 trial. Lancet. 2015;386(9999):1137-46.

51. McInnes IB, Kavanaugh A, Gottlieb AB, Puig L, Rahman P, Ritchlin C, et al. Efficacy and safety of ustekinumab in patients with active psoriatic arthritis: 1 year results of the phase 3 , multicentre, double-blind, placebo-controlled PSUMMIT 1 trial. Lancet. 2013;382(9894):780-9.

52. Ritchlin C, Rahman P, Kavanaugh A, McInnes IB, Puig L, Li S, et al. Efficacy and safety of the anti-IL-12/23 p40 monoclonal antibody, ustekinumab, in patients with active psoriatic arthritis despite conventional non-biological and biological anti-tumour necrosis factor therapy: 6-month and 1-year results of the phase 3, multicentre, double-blind, placebo-controlled, randomised PSUMMIT 2 trial. Ann Rheum Dis. 2014;73(6):990-9.

\section{Submit your next manuscript to BioMed Central and we will help you at every step:}

- We accept pre-submission inquiries

- Our selector tool helps you to find the most relevant journal

- We provide round the clock customer support

- Convenient online submission

- Thorough peer review

- Inclusion in PubMed and all major indexing services

- Maximum visibility for your research

Submit your manuscript at www.biomedcentral.com/submit 